\title{
Integration modes, global networks, and knowledge diffusion in overseas $M \& A s$ by emerging market firms
}

Article

Accepted Version

Li, F., Chen, Y. and Liu, Y. (2019) Integration modes, global networks, and knowledge diffusion in overseas M\&As by emerging market firms. Journal of Knowledge Management, 23 (7). pp. 1289-1313. ISSN 1367-3270 doi:

https://doi.org/10.1108/jkm-03-2018-0204 Available at https://centaur.reading.ac.uk/84451/

It is advisable to refer to the publisher's version if you intend to cite from the work. See Guidance on citing.

To link to this article DOI: http://dx.doi.org/10.1108/jkm-03-2018-0204

Publisher: Emerald

All outputs in CentAUR are protected by Intellectual Property Rights law, including copyright law. Copyright and IPR is retained by the creators or other copyright holders. Terms and conditions for use of this material are defined in the End User Agreement.

www.reading.ac.uk/centaur 
Central Archive at the University of Reading

Reading's research outputs online 


\title{
Integration modes, global network, and knowledge diffusion of overseas M\&As by emerging market firms
}

\begin{abstract}
Purpose - This paper examines how integration modes impact the acquirer knowledge diffusion capacity of overseas M\&As effected by emerging market firms, and the role played by the global innovation network position of the acquiring firms in affecting this relationship.

Design/methodology/approach - Through the use of structural equation modelling and bootstrap testing, the hypotheses are tested by drawing upon a sample of 102 overseas M\&As effected by listed Chinese manufacturing companies.

Findings - The results show that acquirers from emerging countries are unable to increase the knowledge diffusion capacity unless they choose the right post-merger integration mode. This paper also finds that the relationship between integration mode and knowledge diffusion is channelled through the centrality and structural holes of acquirers in the global innovation networks. When considering the combinations of different resource similarities and complementarities of the acquired firms, differences emerge in the integration model and network embedded path of acquirers in emerging countries.

Practical implications - Emerging market multinational enterprises should consider post-merger integration as a crucial facilitator to the crafting of global innovation network positions that promote knowledge diffusion. The choices of integration mode and brand management autonomy should be matched with the resource similarities and complementarities that exist between the acquirer and target firms.

Originality/value - Based on the resource orchestration theory and by focussing on network centrality and structural hole as the crucial links, this study provides a nuanced understanding of the relationship between post-merger integration and knowledge diffusion, and sheds light on latecomer firms from emerging countries.
\end{abstract}

Keywords: innovation network; knowledge diffusion; overseas M\&As; resource orchestration; integration mode, micro-foundation

Article Classification: Research paper 


\section{Introduction}

Merger and acquisition (M\&A) activities effected by emerging markets multinationals (EMNEs) have considerably increased in the last few decades (Rao-Nicholson et al., 2016; Liu and Meyer, 2018). EMNEs prominently pursue cross-border M\&As to access developed economies, with the US, Canada, and Europe being primary destinations due to their leading technology and innovations, and to their lucrative markets (Caiazza et al., 2017; Liu et al., 2018; Liu and Vrontis, 2017; Rao-Nicholson and Salaber, 2015). The acquiring firms can gain access to the research and development (R\&D) resources of their acquisition targets in host countries and accelerate knowledge diffusion and technology spillover to their home country industries through overseas technology sourcing M\&As (Yoon and Lee, 2016). However, the key to achieving the ' $1+1>2$ ' synergistic effect and to improving knowledge diffusion in M\&As is post-merger integration (PMI) (Zaheer et al., 2013). Previous research uncovered the 'lighttouch integration' mode adopted by Chinese MNEs in their overseas M\&As (Liu and Woywode, 2013), highlighting the importance of absorptive capacity and cultural differences. Furthermore, compared to their longer-established counterparts in the developed world, EMNEs may face higher challenges and difficulties in managing the employees and knowledge of their overseas acquisition targets (Khan et al., 2018). Recent research highlighted how the integration mode can significantly affect knowledge management in EMNE M\&As, such as reverse knowledge transfer (Liu and Meyer, 2018). However, the existing research failed to articulate how and to what extent global innovation network positioning may affect knowledge diffusion.

Liabilities of emergingness and country of origin have been studied from various perspectives, owing to the often close relations maintained with home-country governments, the threat of financial protectionism, the loss of key national strategic assets, and whether home-based management practices can be transferred from advanced economies (Buckley et al., 2017; Rao-Nicholson et al., 2016). Against the backdrop of such liabilities, the studies conducted on the PMI of EMNEs found that preserving the employees and granting autonomy to the top management teams (TMTs) of the targets firms can help EMNEs to gain legitimacy in their host markets (Kamoche and Siebers, 2014; Khan et al.,2018). Owing to the importance of cultural differences and to their own lack of absorptive capability, Chinese MNEs often adopt a 'light touch' integration approach towards their acquired subsidiaries (Liu and Woywode 2013; Xing et al., 2017). However, current studies are mainly focussed on the degree of structural integration imposed on, and on the autonomy granted to target firms (Zaheer et al.,2013); thus, in the EMNE context, the understanding of the resource interactions that take place between the acquiring and target firms in the post-merger integration stage is limited. This paper attempts to fill this important theoretical gap from a micro-foundational perspective. For example, after its acquisition of the Swedish Volvo company in 2010, the Zhejiang Geely Holding Group (Geely) - a private Chinese automotive enterprise-integrated and introduced Volvo's high-end automobile business to the Chinese domestic 
market, and localized the Volvo production while preserving the high autonomy of Volvo's TMT (Yakob et al., 2018). Furthermore, there is an urgent call to identify the linkages between critical success factors within each M\&A stage and between the pre- and post-merger stages (Haleblian et al., 2009; Weber et al., 2011; Gomes et.al, 2013). Therefore, by extending the extant research on granting of autonomy with a more nuanced understanding, this paper aims to investigate EMNE knowledge management from the more microcosmic perspective of resource integration and to identify the factors explaining the performance variance in the post-merger phase.

A large part of the research on PMI combines the knowledge-based view by proposing that an important goal of PMI is to facilitate knowledge transfer between the acquiring and target firms for the creation of synergies (Lakshman, 2011; Sarala et al., 2016). Although several of the extant theoretical studies on knowledge transfer in M\&As have been instrumental (Sarala et al., 2014; Aklamanu et al., 2015), they failed to reach a consensus (Aklamanu et al., 2015; Junni et al., 2015); thus, the relationship between integration level and knowledge transfer awaits theoretical articulation and empirical examination. Moreover, research has suggested that M\&As cannot be seen as isolated bilateral relationships; the behaviours of network embeddedness (Wang and Zajac, 2007; Lin et al., 2009). Sarala et al. (2017) also point out that the main findings of prior research on global M\&As have only focussed on the level of integration of the decision-making power of the top management, while the reactions of actors external to the organizational boundaries - e.g. customers, suppliers, and partners - have been largely neglected. We argue that the focus of the study of the knowledge flow in M\&As should not be limited to within the boundaries of the acquiring and target firms (Sarala et al.,2016), but also consider its diffusion in global networks (Lin et al., 2009; Degbey and Pelto, 2013; Wang et al., 2014).

EMNEs face challenges linked to of their 'liability of emergingness' and are often the first generation of firms venturing outside their home countries (Madhok and Keyhani, 2012), depending significantly on home country market scale (Buckley et al., 2017;Yakob et al.,2018) and industrial development and cooperation (Patel et al., 2014). Therefore, the diffusion of knowledge to local industries in the wake of EMNE M\&As can play an important role in EMNE participation in global competition. However, there is a lack of understanding of the mechanisms by which inter-organization knowledge diffusion within the same industry occurs after EMNE M\&As. Given the network embeddedness of global innovation and resource interaction in M\&As, our research question is: "What are the mechanisms for the diffusion of knowledge from acquiring to domestic firms in EMNE M\&As?

The theoretical contributions of this study are threefold. First, by examining the interaction of resources, such as business and brand integration in EMNE M\&As, it provides deeper insights and distinguishes the actual PMI factors that explain variance in post-merger performance. Second, this paper contributes to the M\&A research from a micro-foundational perspective by connecting resource similarities and complementarities in the pre-merger stage, and integration modes in the post-merger stage in explaining 
the performance of the diffusion of knowledge in the EMNE context. In so doing, we provide a more nuanced understanding of resource integration of EMNEs and its varying effects on knowledge diffusion. Third, this paper contributes to the management of knowledge in international M\&As by analysing the effects of integration mode on knowledge diffusion from a network perspective. Specifically, our findings highlight the important role played by the global network position of the acquiring firm and its impact on inter-organization diffusion of knowledge from acquiring to domestic firms within the same industry in the post-M\&A phase.

This paper is organized as follows. First, we review the literature on post-merger integration, knowledge diffusion, global innovation network position, and develop hypotheses accordingly. Next, we describe the research design, the empirical contexts, and the data analysis. Subsequently, we present the empirical findings obtained by testing our hypotheses using data drawn from Chinese manufacturing firms. We conclude by outlining the theoretical and managerial implications of this study and by suggesting future research directions.

\section{Literature review and hypotheses development}

\subsection{Post-merger integration in M\&As}

Post-merger integration research has received significant attention in the M\&A scholarly community (Weber and Tarba, 2009; Tarba et al., 2017). The post-merger integration stage may significantly impact post-merger technological innovation and knowledge diffusion in M\&As (Paruchuri et al., 2006; Puranam et al., 2006). Previous research uncovered how the level of organizational integration can have both positive and negative effects on knowledge diffusion. This dilemma may be especially salient in technology-sourcing M\&As, which are often motivated by the desire to obtain and transfer tacit and socially complex knowledge-based resources (Ranft and Lord, 2002; Weber et al., 2009). High levels of integration have positive effects on synergy by bringing together - i.e., sharing and redeploying - the necessary resources from the acquirer and target firms (Cording et al., 2008) while, at the same time, bringing about changes in operational patterns and valuable R\&D routines, and producing undesirable integration costs due to employee resistance and culture clashes (Slangen, 2006).

In a recent comprehensive review, Graebner et al., (2017:2) offered a more inclusive definition of PMI; one that comprises multiple sub-processes and is focussed on the integration of resources to create value, as "the multifaceted, dynamic process through which the acquirer and acquired firm or their components are combined to form a new organization." In a similar vein, research has called for the adoption of an integrative perspective on the interdependencies of the M\&A process (Bauer and Matzler, 2014). The connections between pre- and post-merger factors are critical for the success of M\&As 
(Haleblian et al., 2009; Weber et al., 2011; Gomes et.al, 2013). The resource similarity and complementarity that exist between the acquiring and target firms are recognized as determinants of the integration mode. For example, Bauer and Matzler (2014) found that strategic complementarities increase the degree of integration, but cultural similarities have the opposite effect. Zaheer et al. (2013) argued that integration and autonomy are not the opposite extremes of a single continuum when complementarities — rather than similarities - are the primary source of synergy, leading to high levels of both integration and autonomy. However, the role played by resource similarity and complementarity in the integration mode and their impact on M\&As still awaits empirical investigation and theoretical articulation.

EMNEs prefer to use M\&As as the entry mode in their globalization endeavours, especially for the technological upgrading acquisitions conducted in advanced economies by manufacturing firms (Liu and Vrontis, 2017). Some pioneering work found that Chinese firms tend to adopt 'light-touch integration' approaches in their cross-border M\&As (Liu and Woywode, 2013). This observation resonates with those made by other recent studies that acknowledge that the granting of autonomy to target firm TMTs is widely effected by EMNEs attempting to invest and integrate in developed countries (Kamoche and Siebers, 2014; Khan et al., 2018). Liu and Woywode (2013) found that a light-touch integration may help Chinese MNEs overcome the difficulties stemming from cultural differences and from their own lack of absorptive capability towards their acquired subsidiaries. The level of business integration describes the extent to which the daily operation and business of the target firm are incorporated into the acquiring one (Zaheer et al., 2013), while brand management autonomy is defined as the extent to which the acquirer delegates the target management in regard to decision-making within the target brand (Shi et al., 2017). In the context of EMNE M\&As, Liu et al. (2018) uncovered the dynamics of brand management that occur in the wake of Chinese overseas acquisitions, adding important understanding to PMI in EMNE M\&As. However, according to Graebner et al. (2017), the microcosmic understanding of the underlying resource interactions that occur during PMI-including business integration, brand management, and their impact on knowledge diffusion — is still limited.

\subsection{Knowledge diffusion in M\&As}

Knowledge management constitutes as an important topic in M\&A (Sarala et al., 2016) and technology development research. The exchange of knowledge between firms is a phenomenon frequently observed during the phases of product development, production, and diffusion of technological innovations $(\mathrm{Mu}$ and Lee, 2005). The extant research has acknowledged the benefits of pursuing M\&As for knowledge transfer purposes, implying relatively high levels of integration (Ranft and Lord, 2002; Ranucci and Souder, 2015). Research has highlighted the distinctions between the transfer of knowledge from acquirer to target and from target to acquirer-which is also called reverse knowledge transfer-in the M\&A process (Junni et al., 2015; Sarala et al., 2016; Graebner et al., 2017). For instance, one recent 
study examined the reverse transfer of knowledge from advanced economy targets to Chinese acquirers by highlighting the role played by boundary spanners and collaborative HRM practices (Liu and Meyer, 2018). However, little attention has been paid to the diffusion of inter-organizational knowledge from the acquiring to the domestic firms within the same industry, which is particularly important for the knowledge management of EMNE enterprises (Madhok and Keyhani, 2012).

Importantly, knowledge diffusion and transfer differ in several aspects. First, in M\&As, knowledge transfer occurs mainly between the acquiring and target firms (Sarala et al., 2016), while knowledge diffusion takes place between one flagship firm and multifaceted agents. Mu and Lee (2005) suggested that the diffusion of knowledge from multinational enterprises (MNEs) to firms in less developed countries is often regarded as a major source of the latter's technical progress and productivity growth. Second, knowledge transfer is not a sufficient condition for the effective diffusion of knowledge. Diffusion is completed only when the transferred knowledge is internalized and translated into the capabilities of domestic firms (Ernst and Kimb, 2002). Using data drawn from the Indonesian manufacturing sector, Todo and Miyamoto (2002) found that domestic firms can absorb knowledge effectively only from MNEs in the same industry sector. Thus, knowledge diffusion, in this paper, refers to domestic firms internalizing knowledge transferred from MNEs in the same industry sector and translating it into innovation capabilities after said MNEs complete an overseas M\&A.

More recently, with the rapid growth of network science, the diffusion of knowledge in interorganizational networks has attracted much research attention (Luo et. al, 2015). Knowledge diffusion along different types of network structures has been extensively studied-e.g., on scale-free networks (Lin and Li, 2010) and on small-world networks (Kim and Park, 2009). Furthermore, Lin et al. (2010) found that knowledge diffusion in an industry sector depends on a strong flagship firm becoming a network leader that controls the convergence, diffusion, and spillover of industrial network resources and leads the industrial technology structure (Lin et al., 2010). Although the diffusion of knowledge from MNEs to domestically owned firms has received research attention (Ernst and Kimb, 2002; Mu and Lee, 2005), little attention has been paid to the diffusion of inter-organizational knowledge in the post-M\&A integration stage from acquiring to domestic firms within the same industry sector. Specifically, what mechanisms for knowledge diffusion through overseas M\&As are influenced by the global network position of the acquiring firm?

\subsection{Global network position}

Innovation networks are an important avenues by which different enterprises can go beyond their organizational boundaries to acquire external technology and innovation resources (Freeman, 1991). 
Awazu (2004) showed that companies can gain comparative advantages by integrating online knowledge. Recently, firms have been going beyond their boundaries to foster learning activities at both the inter-firm and inter-industry levels and on both the national and international scale (Alguezaui and Filieri, 2010). The theory on latecomer firms points out that global networks and the increasingly complex and dispersed nature of knowledge force enterprises in emerging countries to 'catch up' by embedding themselves in global innovation networks (Herrigel et al., 2013). Innovation network theory has been applied to analyse inter-firm diffusion of innovation cooperation knowledge (Hanaki, 2010). Network dynamic theory points out that a network will affect the actions of individuals within it; at the same time, interactions among individuals can also affect the impact of the overall network structure (Rowley and Baum, 2008). Enterprises that occupy dominant network positions exert more control over resources and hold more advantages in innovation activities (Lin et al., 2009). Network centrality and structural holes are the most relevant network position indicators for technology innovation and knowledge diffusion, as has widely been confirmed by network research (Zaheer and Bell, 2005; Wang et al., 2014; Iurkov and Benito, 2017). Network centrality points to the extent to which a firm occupies a central position in relation to its ties to other network members and to its ability to span multiple sources of knowledge (Lin et al., 2009; Tortortiello et al., 2012). Compared with network centrality, structural holes reflect the extent of access to other network members; they emphasize the strategic controls of such access and the ability to connect to partners with heterogeneous resources (McEvily and Zaheer, 1999; Burt, 2002).

Recent works suggest that M\&As cannot be seen as isolated bilateral relationships; the behaviours of network embeddedness should take into account external actors located outside the organizational boundaries - e.g., customers, supplies and partners (Wang and Zajac, 2007; Lin et al., 2009; Sarala et al., 2017). Degbey and Pelto (2013) found that any changes taking place during the PMI of a bilateral relation are likely to affect the actions of the direct partners in the network. Then, the changes triggered by an acquisition may spread further at the network level—i.e., to indirect relationships — and change the network structure. Patel et al. (2014) indicated that the balance of the local and foreign networks can accelerate the internationalization speed of enterprises. Exequiel and Anoop (2018) suggested that overseas M\&As are an effective means for acquirers to improve knowledge-enhancing positions—such as centrality or structural holes - to gain network synergy. However, the identification of what kind of PMI mode can realize network synergy after the completion of M\&A transactions is still missing in the existing research.

\subsection{Global network position and knowledge diffusion}

The notion of network centrality points to the extent to which a firm occupies a central position in relation to its ties to other network members (Lin et al., 2009) and to its ability to span multiple sources of knowledge (Tortortiello et al., 2012). Organizations holding greater global network centrality have 
higher possibilities to access information and resources (Lin et al., 2009). The extensive strategic knowledge held by acquiring firms through their global innovation networks, such as diversity of technology standards (Banalieva and Dhanaraj, 2013), demand for differentiation, and R\&D resources can diffuse to domestic firms in same industry (Wang et al., 2015) through domestic technology cooperation, module production, local supply chains, and even reverse engineering (Wu and Rui, 2007). Besides, MNEs with high network centrality, such as 'global network flagships' that integrate their dispersed supply, knowledge, and customer bases into global or regional networks can boost international knowledge diffusion, providing new opportunities for the development of capabilities by local suppliers in emerging countries (Ernst and Kimb, 2002). Under pressure from central firms, local suppliers have a strong incentive to internalize the transferred knowledge through various forms of knowledge conversion. As the leading enterprise in the industry, the acquirer promotes the diffusion of new knowledge within the industrial network and the use of high technology and process standards (Cho et al., 2012). Oehme and Bort (2015) found that the organizational mimetic isomorphism of their peers impacts the internationalization of young small- and medium-sized enterprises (SMEs). The early adopters of certain practices (internationalization, $R \& D$, and innovation processes) do so mostly on economic calculus, while later adopters additionally seek to send a signal about their own legitimacy by imitating the practices of earlier ones. Acquirers that improve their global network centrality by overseas M\&As earn higher status and reputation (Koka and Prescott, 2008), which causes SMEs in the home industry sector to imitate their R\&D investment or innovation cooperation decisions, and finally improve their capabilities for the absorption of the knowledge diffused by the acquiring firms. In this way, the greater global network centrality of acquiring firm helps the effective diffusion of knowledge in domestic industry sectors.

Hypothesis 1a. The higher the level of centrality held by the acquirer in a global innovation network, the stronger the diffusion of its knowledge after overseas M\&As.

A firm's network structural hole position refers to its brokerage location between two otherwise disconnected firms in the network (Lin et al., 2009). Compared with network centrality, which reflects the extent of a firm's access to other network members, structural holes emphasize the strategic control of such access (Burt, 2002) and the ability to connect to partners with heterogeneous resources (McEvily and Zaheer, 1999). Further, the knowledge diffusion of firms occupying more structural holes will be weaker than that of firms with high centrality; this is due to the broker firm's ability to control and manipulate the flow of knowledge (Wang et al., 2014) to maintain a technological advantage inside its organizational boundaries (Iurkov and Benito, 2017) and obtain control benefit originating from its 'tertius gaudens' position (literally, 'the third who benefits') (Burt, 1992). However, the structural holes of an acquiring firm can also help the effective diffusion of knowledge in a domestic industry sector in two ways. Structural hole positions provide the broker with efficient access to the private information 
of other disconnected firms, increasing its chance of finding undervalued knowledge (Lin et al., 2009). As a higher level of brokerage implies the elimination of redundant ties, an acquiring firm with a higher level of brokerage would be able to more efficiently employ scarce time, energy, and attention for knowledge diffusion (Wang et al., 2014). Overall, an acquiring firm controlling more structural holes is able to effectively and more precisely transfer the knowledge needed for cooperation to designated partners in the domestic industry sector. On the other hand, EMNEs come from countries that are 'playing catch-up' (Palepu et al., 2010) and thus face 'liability of emergingness' (LOE) challenges (Madhok and Keyhani, 2012). They are the first generation of firms venturing abroad from their home countries, with limited knowledge of organizing global supply chains in time. Local collaborations create cost-based competitive advantages and faster production innovation (Patel et al., 2014). EMNEs have to transfer the production and R\&D knowledge necessary to improve the ability of domestic supply firms to enhance their competitive advantages in the international market (Ernst and Kimb, 2002). Besides, emerging market industry SMEs do not have the capacity needed to participate independently in international production divisions and innovation cooperation (Oehme and Bort, 2015). They need their acquiring firm to act as a hub between the global innovation network and the local industrial one for information transfer and knowledge diffusion and submit to its control when their internationalization ability is weak (Wang et al., 2015). Thus, the acquirers will keep transferring heterogeneous knowledge and timely information (Burt, 1992) to local firms through core-periphery innovation divisions or domestic supply chains when they occupy structural hole positions.

Hypothesis 1b: The higher the acquirer's level of structural holes in an innovation network, the stronger its knowledge diffusion in the wake of overseas EMNE M\&As.

\subsection{The role played by resource recognition in post-merger integration and global network position: a micro-foundational perspective}

In management studies, the micro-foundational movement has attracted increasing and significant scholarly attention (Felin et al., 2015). A nuanced understanding from a micro-foundational perspective of resource recognition in collaborative partnerships, such as M\&As, can lead to explaining processes and macro-level outcomes (Liu et al., 2017). Thus, it is worth distinguishing between resource similarity and resource complementarity. Resource similarity describes the extent to which the acquiring and acquired firms share common technologies, competencies, markets, or products (Slangen, 2006). Resource complementarity refers to the potential to create greater value by combining different but mutually reinforced technologies, markets, or products (Makri et al., 2010). In this paper, we define resource complementarity in relation to the different strategic, marketing, and human resources held by acquirer and target, the combination or re-configuration of which can potentially create value that could not be obtained by each individual firm before the M\&A (Helfat and Peteraf, 2003). Based on resource orchestration theory (Sirmon et al, 2011) from a micro-foundational perspective, we argue that the 
integration mode adopted should be based on the recognition of the resource similarity and complementarity that exists between the acquirer and the target firm. An appropriate integration mode can promote knowledge diffusion through configuration in the global innovation network.

\section{Integration mode and network position when the resources of the acquirer and target firms present} strong similarity and weak complementarity.

Resource similarity represents the compatibility of the routines related to knowledge management between acquirer and target (Wang et al., 2017); it can facilitate mutual understanding and the exchange of existing knowledge (Cohen and Levinthal, 1990). Additionally, similarity can ensure the smooth combination of resources and reduce integration costs (Zaheer et al., 2013). When resources are recognized as presenting strong similarity and weak complementarity, a high level of business integration enables the acquirer to connect more closely with the target's network. Alongside strong similarity, homogeneity preferences confer to the acquirer the ability required to innovate and cooperate with the network partners of the target (Monge and Contractor, 2003). Thus, it further improves the acquirer's centrality in the global innovation network; integration will make the merged firm into a superstar (Borgatti and Halgin, 2011) and promote the efficiency of sharing similar resources. The knowledge spillovers of the merged firm generate positive feedback, which can attract more global innovation partners though the preference attachment effect (Hanaki et al., 2010). A high integration of similar resources will strengthen the acquirer's centrality in the global innovation network. An acquirer that improves its global network centrality can transfer knowledge through its business relationships with the upstream and downstream companies in the local industry sector (Qian et al., 2010).

While network centrality focusses on the richness of network connections, structural holes, on the other hand, emphasize such connections' heterogeneity and diversity. When resource similarity is strong, the acquirer needs to sever any redundant R\&D cooperation relationships and business ties (Qian et al., 2010), reallocate resources in the global network, and retain its heterogeneous network connections through deep business integration. Thus, a high level of business integration will enhance the acquirer's structural hole in the global innovation network, which can lead to knowledge diffusion.

Overseas M\&As generate opportunities for companies to connect with brands that are already established in developed markets, and to transfer or to reposition their own (Liu et al., 2018). However, in the presence of too much resource similarity between acquirer and target, especially in relation to market and product resources, granting too much target brand management autonomy will inevitably lead to the brands from the acquirer and target firm to compete for core resource, causing brand perception confusion in the original customers (Vũ et al., 2009). In this case, emerging market firms conducting international M\&As should adopt unified global brand management strategies aimed at constructing coherent organizational identities (Park et al., 2018). In the presence of high levels of target 
brand autonomy and strong resource similarity, the target TMT tends to resist the changes brought about by restructuring (Zollo and Singh, 2004), to hinder effective control of the target resources by the acquirer firm, and to impede the acquirer from directly accessing heterogeneous network resources and improving its network position. Thus:

Hypothesis 2a. In the presence of strong resource similarity and weak resource complementarity between the acquiring and acquired firms, high levels of business integration and low levels of brand management autonomy are more likely to improve the acquirer's network centrality.

Hypothesis 2b: In the presence of strong resource similarity and weak resource complementarity between the acquiring and acquired firms, high levels of business integration and low levels of brand management autonomy are more likely to strengthen the acquirer's network structural hole.

Integration mode and network position when the resources of the acquirer and target firms present weak similarity and strong complementarity.

When the resources of the acquirer and target firms present weak similarity and strong complementarity, the innovation networks of the acquirer and target firms will feature differentiated information, perspectives, and problem solutions (Lin et al., 2010). The acquirer will face severe technology absorption and brand management issues, and the target TMT needs to be entrusted with a degree of autonomy suited to manage the complementary resources (Puranam et al., 2006; Paruchuri et al., 2006). High levels of business integration will lead to high integration costs, resulting in the disruption of the target firm's sales networks, product channels, and social relationships that are not familiar to the acquirer.

When complementarity is strong, the brands of the acquirer and target firms can achieve harmonization, which refers to cost reduction and growth synergy for both brands through collaboration (Vũ et al., 2009). However, the trust and cooperation of the target is key to brand management and knowledge transfer, as the acquirer is not familiar with target's resources. Zhang et al. (2015) pointed out that, in China, management practices are, to a certain extent, based on guanxi networks, which are unlike those found in developed countries. Thus, talent retention is especially important when the acquirer is not familiar with the target's resources. Low levels of business integration and high levels of brand autonomy will help the acquirer to gain the trust of the target and to successfully embed itself into the global innovation network, and will promote the acquirer's network centrality through a close connection with the target firm (Lin et al., 2009). Moreover, through its endorsement of the target and 
a successful integration, the acquirer will attract more innovative cooperation and further enhance its centrality.

At the same time, when resources are recognized as presenting weak similarity and strong complementarity, low levels of business integration and high levels of brand autonomy can enhance the value of the relationship between the acquirer and the target, and successfully set up a hub between the global innovation network and the local industrial one for information transfer and knowledge dissemination. This integration mode can ensure the preservation of the target firm's sales networks, product channels, and social relationships that are not familiar to the acquirer. Moreover, the acquiring firm can enhance its structural hole in the global innovation network by making more heterogeneous connections, which will ultimately promote knowledge diffusion. Thus:

Hypothesis 3a. In the presence of weak resource similarity and strong resource complementarity between the acquiring and acquired firms, low levels of business integration and high levels of brand management autonomy are more likely to improve the acquirer's network centrality.

Hypothesis 3b. In the presence of weak resource similarity and strong resource complementarity between the acquiring and acquired firms, low levels of business integration and high levels of brand management autonomy are more likely to strengthen the acquirer's network structural hole.

\section{Integration mode and network position when the resources of acquirer and target firms present strong similarity and strong complementarity.}

The degrees of business integration and of target brand management autonomy can reach a certain level at the same time (Zaheer et al., 2013). Granting the acquired firm some decision-making autonomy is likely to create goodwill among its employees and create an atmosphere that is more conducive to collaboration during the PMI stage (Tarba et al., 2017). Especially in the presence of strong resource similarity and complementarity, the acquirer must structure the merged business to achieve coordination among the two original firms' resources, and also needs to gain the trust of the target firm to access the latter's tacit knowledge assets and to deal with the changing trends of complex technology. When only strong resource similarity exists, high levels of business integration will enable the acquirer to connect closely with the target's innovation network and improve the acquirer's centrality in the global innovation network; At the same time, high levels of business integration will lead to the severing of any redundant $R \& D$ cooperation relationships and to the retaining of any heterogeneous network connections. Thus, high levels of business integration will strengthen the acquirer's structural hole in 
the global innovation network. However, when resource similarity and complementarity coexist, certain resources will not be familiar to the acquirer. High levels of business integration will generate friction costs, resulting in the severing of some valuable network relationships of the target firm, which will hinder the improvement of the acquirer's network position in the global innovation network.

When only resource complementarity is strong, high levels of brand autonomy will help the acquirer to gain the target's trust and to successfully embed itself in the global innovation network, and the acquirer's network centrality will be promoted by its close connection with the target firm; at the same time, high levels of brand autonomy can ensure the preservation of the target firm's sales networks, products channels, and customer relationships that are not familiar to the acquirer (Paruchuri et al., 2006). Moreover, the acquiring firm can strengthen its structural hole in the global innovation network by making more heterogeneous connections. However, when resource similarity and complementarity coexist, high levels of target brand autonomy will impede the acquirer in accessing any heterogeneous network resources and directly hinder it in improving its network position in the global innovation network.

Figure 1 shows our theoretical framework that identifies business integration and brand autonomy as explanatory factors influencing knowledge diffusion in the overseas M\&As conducted by EMNEs. The global innovation network position (centrality and structural hole) of the acquiring firm plays a mediating role, while any resource similarity and complementarity that exist between acquiring and target firms moderate the relationship between integration and network position. Theoretically rooted in the M\&A process context (Haleblian et al., 2009; Weber et al.,2011; Gomes et al, 2013) and resource orchestration perspective (Sirmon et al., 2011), we extend a framework that connects resource similarity and complementarity in the pre-merger stage and integration mode in the post-merger one in explaining the performance of knowledge diffusion in the EMNE context. Therefore, when resource similarity and complementarity coexist, moderate levels of business integration (lower than those linked to strong similarity and weak complementarity) and moderate levels of brand autonomy (lower than those associated with weak similarity and strong complementarity) would be the best option. Thus:

Hypothesis 4a. In the presence of strong resource similarity and strong resource complementarity between the acquiring and acquired firms, high levels of business integration and high levels of brand management autonomy are more likely to improve the acquirer's network centrality.

Hypothesis 4b. In the presence of strong resource similarity and strong resource complementarity between the acquiring and acquired firms, high levels of business integration 
and high levels of brand management autonomy are more likely to strengthen the acquirer's network structural hole.

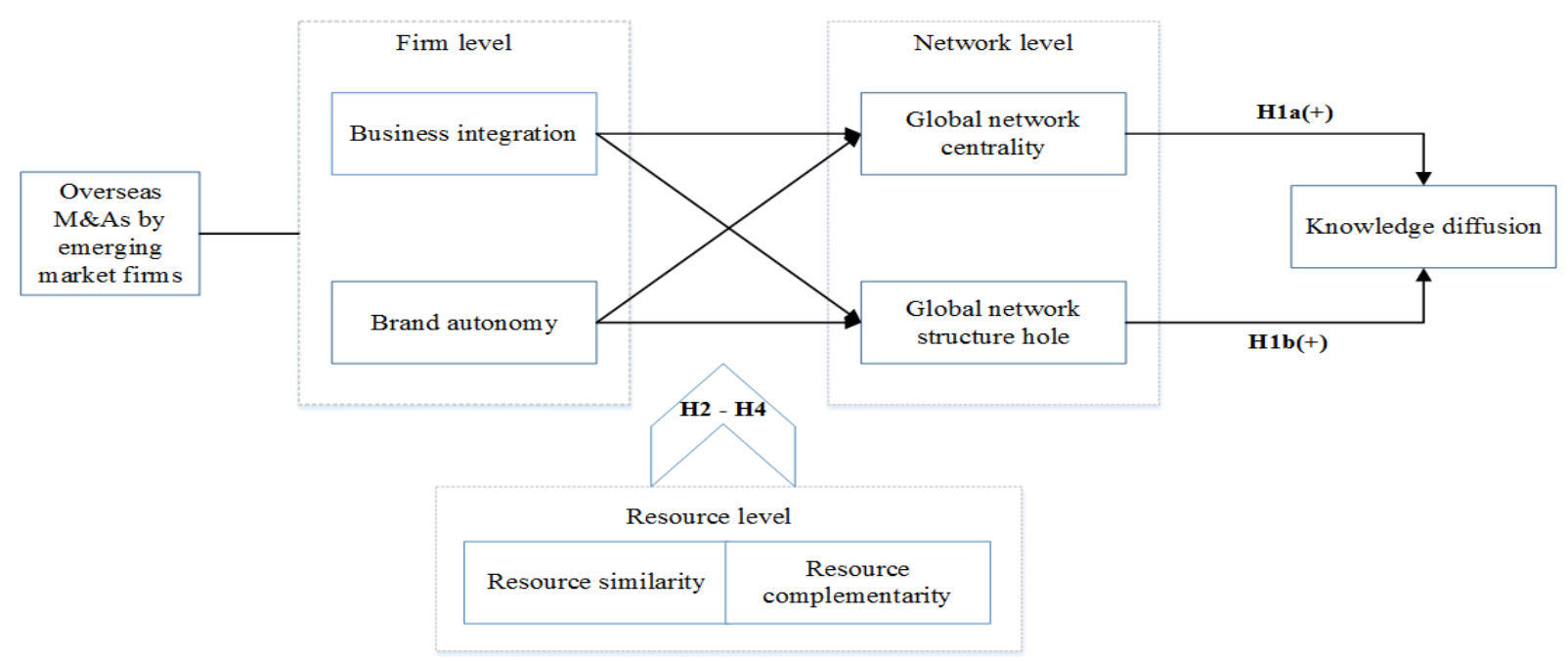

Figure 1 Theoretical framework

\section{Method}

\subsection{Sample and Data}

In this paper, we aim to gain an enhanced understanding of the knowledge diffusion achieved by EMNEs through M\&As by examining the case of overseas M\&As conducted by Chinese firms, which are on the increase and constitute an important example of EMNEs venturing into advanced economies (Liu and Vrontis, 2017; Xing et al., 2017). This approach is aligned with those taken by previous studies investigating brand management (Liu, et al, 2018), servitization (Xing, et al, 2017), and reverse knowledge transfer (Liu \& Meyer, 2018) in the context of EMNE M\&As. In 2017, China's outward foreign direct investment (OFDI) amounted to US\$158.29 billion, accounting for more than $10 \%$ of the global share for two consecutive years (Ministry of Commerce of the People's Republic of China, 2018). In China's total OFDI, the proportion of overseas M\&As increased from 37.37\% in 2015 to $75.57 \%$ in 2017 (Ministry of Commerce of the People's Republic of China, 2018), showing how overseas M\&As are a dominant mode of international market entry for Chinese MNEs.

Our sample, which we obtained from the BVD Zephyr database, consisted of technology-sourcing overseas M\&As conducted by Chinese manufacturing firms between 2001 and 2012. The reason for choosing 2001 as the starting point of our study was that that was the year China joined the WTO, and the number of overseas M\&As conducted by Chinese firms increased significantly. The reason for choosing 2012 as the end point of our study was that the performance of M\&As has been proved to lag 
behind their implementation (Makri et al.,2010); thus, a time window of two or three years should be allowed to observe post-merger knowledge diffusion. As the industry data collected by the China National Bureau of Statistics were updated to 2015, 2012 was a suitable endpoint for our sample. The sample M\&As were 'completed' overseas deals in which Chinese listed firms had been the acquirers. In addition, we followed the well-established technological acquisition literature and filtered out our sample by several criteria to isolate technology-sourcing M\&As. We limited our sample to manufacturing industry sectors (SIC codes 20-39) and eliminated M\&As that had clearly not been aimed at technology sourcing, based upon searches of newswires and M\&A announcements (Sears and Hoetker, 2014). Based on the selection criteria for technology-sourcing M\&As found in Ahuja and Katila's (2001) and Makri et al.'s (2010) studies, the target firms were limited to those located in developed countries, as defined by the International Monetary Fund. As the same time, we eliminated those M\&As in which the acquirer had not been listed on the Mainland Chinese stock market or did not hold any patents. To ensure that the acquirer had control rights over the target firm, the M\&A equity ratio of our sample was set to be higher than $50 \%$. After implementing these filters, our final sample contained 102 Chinese firm instigated technology-sourcing overseas M\&As. Table 1 shows the industry sector, timing, and target firm countries of the M\&As in our sample. The 2008 global financial crisis had a significant impact on the number of overseas M\&As initiated by Chinese firms. In our sample, there are 33 M\&As dating from 2001 to 2008, and 69 occurring after 2008. However, research has shown that the performance of cross-border M\&As initiated by Chinese MNEs after 2008 did not significantly differ from that of cross-border M\&As effected during the 2001-2007period, especially those involving a in high-tech industry sector (Gu and Reed, 2011; Yang and Zhang, 2014).

Table 1 Sample description

\begin{tabular}{c|c|c|c}
\hline $\begin{array}{c}\text { Sample } \\
\text { characteristics }\end{array}$ & Classification standard & Sample size & Percentage (\%) \\
\hline \multirow{5}{*}{$\begin{array}{c}\text { Acquiring firm } \\
\text { industry sector }\end{array}$} & $\begin{array}{c}\text { Electrical machinery and equipment } \\
\text { manufacturing }\end{array}$ & 5 & 4.902 \\
\cline { 2 - 4 } & $\begin{array}{c}\text { Computer communications and } \\
\text { electronic equipment manufacturing }\end{array}$ & 22 & 5.882 \\
\cline { 2 - 4 } & $\begin{array}{c}\text { Automobile transportation equipment } \\
\text { manufacturing }\end{array}$ & 23 & 22.569 \\
\cline { 2 - 4 } & General equipment manufacturing & 8 & 7.843 \\
\cline { 2 - 4 } & Special equipment manufacturing & 16 & 15.685 \\
\cline { 2 - 4 } & Others & 22 & 21.569 \\
\hline \multirow{5}{*}{ M\&A timing } & $2001-2004$ & 7 & 6.863 \\
\cline { 2 - 4 } & $2005-2008$ & 69 & 67.647 \\
\cline { 2 - 4 } & $2009-2012$ & 5 & 4.902 \\
\hline
\end{tabular}




\begin{tabular}{|c|c|c|c|}
\hline \multirow{8}{*}{$\begin{array}{c}\text { Host } \\
\text { country/region }\end{array}$} & United States & 20 & 19.608 \\
\hline & Germany & 21 & 20.588 \\
\hline & Japan & 6 & 5.882 \\
\hline & Hong Kong China & 10 & 9.804 \\
\hline & Italy & 7 & 6.863 \\
\hline & France & 5 & 4.902 \\
\hline & South Korea & 4 & 3.922 \\
\hline & Others & 24 & 23.529 \\
\hline
\end{tabular}

\subsection{Measurement}

Sample classification criteria: resource similarity and complementarity. In this paper, the structural equation model was used for empirical testing. Wang and Zajac's (2007) functions were used to measure resource similarity and complementarity.

Resource similarity. The North American Industrial Classification System (NAICS) was used to measure the resource similarity between the acquiring and acquired firms. We set the resource similarity of each pair of firms to: 1 if the first four digits of their NAICS codes were the same; 0.75 if the first three digits were the same; 0.5 if the first two digits were the same, 0.25 if the first digit was the same; and 0 otherwise.

Resource complementarity. The method used to calculate this variable was adopted from Wang and Zajac (2007), who suggested that more complementary businesses will more frequently be combined within the same firm as they have potential synergy. This method assumes that more related activities will be more frequently combined within the same corporation. If those firms that engage in activity A almost always also engage in activity B, then activities A and B are highly complementary. Thus, we used the degree of complementarity between the NAICS codes of each pair of firms as a proxy for their resource complementarity. From the BVD Zephyr database, we selected all the Chinese listed acquirer firms with more than one NAICS code that had been involved in technology-sourcing overseas M\&As between 2001 and 2012; this resulted in a sample of 176 firms. If a Chinese listed acquirer firm had one pair of NAICS codes at the same time, we concluded that the two activities linked to those codes were complementary. If the same pair of NAICS codes appeared simultaneously in multiple companies, we concluded that the related activities were highly complementary. The complementarity score of such codes (Comij, with $i$ and $j$ denoting the two codes) was calculated as follow:

$$
\operatorname{Com}_{i j}=\left(U_{i j}-\mu_{i j}\right) / \delta_{i j}
$$

where $\mathrm{J}_{\mathrm{ij}}=$ the number of times that the two NAICS codes appeared in the same firm; $\mu_{i j}=\left(N_{i} \times N_{j}\right) / K(N i$ $=$ the number of firms with NAICS code $i ; N_{j}=$ the number of firms with NAICS code $j ; K=$ the total number of firms); and $\delta_{i j}=\sqrt{\mu_{i j} \times\left(1-\frac{N_{i}}{K}\right) \times\left(\frac{K}{K-1}\right) \times\left(1-\frac{N_{j}}{K}\right)}$ 
The sample M\&As were divided into four groups according to the median of the resource similarity and complementarity of their constituting firm pairings: group A, with strong similarity and weak complementarity (37); group B, with weak similarity and strong complementarity (35); group C, with strong similarity and strong complementarity (17); and group D, with weak similarity and weak complementarity (13). We then compared the conduction paths, coefficients of integration, and knowledge diffusion in groups A, B, and C. Group D had little research value because, when both the resource similarity and complementarity between the acquiring and acquired firms are weak, the potential synergy of M\&As is weak.

\section{Knowledge diffusion}

(1) Knowledge diffusion by patent applications. The number of patent applications made within an industry sector is the most widely used measure of industrial knowledge (Sun and Du, 2010). We added the weight of the acquirer firms into the calculation to describe their contributions to the diffusion of knowledge from the global pool to the local industry sector in the wake of an overseas M\&A.

$$
\text { Knowledge diffusion by patent }=\frac{n \sum_{j=1}^{n} b i j}{\sum_{i=1}^{n} \sum_{j=1}^{n} b i j} \cdot P
$$

where $P$ is the number of industry patent applications made in the year of the M\&A; and $\frac{n \sum_{j=1}^{n} b i j}{\sum_{i=1}^{n} \sum_{j=1}^{n} b i j}$ is the weight of the acquirer firms. This is the degree of increase in industrial production needs due to the acquirer enterprise increasing the final demand for a unit. We used the ratio of the acquirer firm's prime sales revenue to the industry's average prime sales revenue: $\sum_{j=1}^{n} b i j$ is the acquirer firm's prime sales revenue; $n$ is the number of firms in the industry sector; and $\sum_{i=1}^{n} \sum_{j=1}^{n} b i j$ is the industry sector's average prime sales revenue. This variable was measured using the average growth rate of patents as an indicator of industrial innovation within the first two years after the M\&A.

(2) Knowledge diffusion by new products. The variable was measured by the sales revenue of new products in an industry sector multiplied by the acquirer's weight, and then calculated by the average growth rate in the first two years after the M\&A. The acquirer-related information was gathered from the annual reports of the listed companies and from the GTA CSMAR database. The industry-related data were derived from the Statistical Yearbook of China's Science and Technology, 2001-2015.

The construction and measurement of the innovation network. Patent cooperation is a research tool widely used in constructing innovation networks (Hanaki et al., 2010). It takes patent citation as an alternative measure of knowledge flow to form an innovation network. The patent data drawn from the United States Patent and Trademark Office (USPTO) contains the most comprehensive and accurate global patent application and reference information, and are widely used in research on international 
technology spillover and innovation networks (Guan and Chen, 2012). First, a Snowball-Sampling approach (Johnson et al., 1989) was applied to determine the boundaries of the innovation network. We started from the patent information of the acquiring and target firms. We searched the USPTO for all patent applications and reference information in which the acquirer firm had been the applicant. All those merged firms that had submitted joint patent applications and patent citations within two years of their M\&A were regarded as nodes of the innovation network. Second, the joint patent application and patent reference information was converted into a corresponding relationship between the acquiring and the target firms. Then, we constructed the adjacency matrix of the innovation network and imported it into the UCINET network analysis software. Finally, we used the NetDraw tool to draw a map of the innovation network's topology. After constructing a global innovation network for each acquirer, we used UCINET to calculate its network centrality and structural holes.

\section{Centrality of the global innovation network:}

(1) Closeness centrality was calculated as follows:

$$
\text { Closeness centrality }=\frac{n-1}{\sum_{i=1}^{n} d\left(p_{i}, p_{k}\right)}
$$

where $n$ represents the number of firms in the network, while $d\left(p_{i}, p_{k}\right)$ represents the path distance between firms $i$ and $j$.

(2) Network power. If a node is connected to another with a higher power, the power of the former will also be improved.

$$
\text { Network power }=\sum A_{i j}\left(\alpha+\beta c_{j}\right)
$$

where $A$ stands for a given adjacency matrix, $c_{j}$ represents the power of nodes connected to the acquirer, and $\alpha$ and $\beta$ are fixed parameters.

\section{Structural hole of the global innovation network:}

(1) Structural hole with network constraint. Burt (1992) suggested that network constraint is the extent to which the network is directly or indirectly concentrated in one link. The higher the network constraint, the fewer the structural holes held by the node (Zaheer \& Bell, 2005).

$$
p_{i j}=\frac{a_{i j}+a_{j i}}{\sum_{k}\left(a_{i k}+a_{k i}\right)}
$$


where $a_{i j}$ is the link weight between $i$ and $j$; and $p_{i j}$ refers to the connection strength of $i$ and $j$. Node $\mathrm{i}$ is constrained by node $\mathrm{j}$ :

$$
c_{i j}=\left(p_{i j}+\sum_{q, q \neq i, q \neq j} p_{i q} p_{q i}\right)^{2}
$$

The sum of the constraint is $c_{i}=\sum_{j} c_{i j}$. The structural hole with constraint is $s_{i}=1-c_{i}$.

(2) Structural hole with hierarchy. It indicates the extent to which network constraint is concentrated in a single node:

$$
h_{i}=\frac{\sum_{j}\left(\frac{c_{i j}}{C / N}\right) \ln \left(\frac{C_{i j}}{C / N}\right)}{N \ln (N)}
$$

where $N$ represents the number of enterprises in the network; and $C$ is the sum of the network constraints of all of the nodes. The structural hole with hierarchy is $s h_{i}=1-h_{i}$.

Business integration. Following Puranam et al. (2009), we collected public information on post-merger business integration through acquisition announcement reports, annual reports, and related news, and assigned it a binary variable. We set the degree of business integration to 1 if the activities of the target firm had been integrated into the operations of the acquirer firm, and to 0 if they had been maintained as an independent business unit or a subsidiary of the acquirer firm.

Brand management autonomy. From the same data source used for the degree of integration, we collected public information on brand management autonomy through acquisition announcement reports, annual reports, and related news in both the GTA CSMAR database and Lexis.com International. In accordance with Colombo et al. (2010), we set the degree of autonomy to 1 if "retain target's brand and top management team" or "high operational independence" appeared in the public information; otherwise, it was set to 0 .

Control variables. We controlled the average GDP growth rate in the two years following each M\&A to account for possible timing differences in the macroeconomic environment. We also controlled the average industrial $R \& D$ investment growth rate over the same period.

\subsection{Confirmatory Factor Analysis, Reliability, and Validity Test}

We used AMOS 17 to test the reliability and validity of the model by means of a confirmatory factor analysis (CFA) model that contained all of the variables (Chadwick et al., 2015). The correlation coefficient of the measurement model is shown in Table 2, and the CFA results are shown in Table 3. Table 3 shows that the chi-squared value of the CFA model was statistically significant ( $\mathrm{p}<0.001)$; and the fitting index was greater than the standard of 0.9. The measurement model fit the data well. Six 
standardized factor loadings were statistically significant $(\mathrm{p}<0.001)$. The Cronbach's alpha values for all of the latent variables were greater than 0.6 , indicating that the reliability of the measurement was acceptable. The average variance extraction (AVE) — which measures the validity of the measurement model (Chen et al., 2015) — of all of the latent variables met the requirement of being greater than 0.5 .

Table 2. The correlation coefficient matrix of the measurement model

\begin{tabular}{llllllllll}
\hline & Mean & S.D. & X1 & X2 & X3 & X4 & X5 & X6 & X7 \\
\hline Business & 0.427 & 0.497 & 1.000 & & & & & \\
Integration & & & & & & & & \\
Brand autonomy & 0.596 & 0.494 & $-0.631^{* * *}$ & 1.000 & & & & \\
Network centrality & 0.198 & 0.256 & $0.61^{* * *}$ & $-0.465^{* *}$ & 1.000 & & & \\
Structural holes & 0.115 & 0.189 & $-0.565^{* * *}$ & $0.695^{* * *}$ & $-0.83^{* *}$ & 1.000 & & & \\
Knowledge & 0.794 & 0.305 & 0.006 & 0.142 & 0.13 & 0.177 & 1.000 & \\
diffusion & & & & & & & & \\
R\&D investment & 0.680 & 0.453 & 0.172 & -0.117 & -0.152 & 0.081 & 0.023 & 1.000 & \\
GDP growth rate & 0.475 & 0.463 & $0.227^{*}$ & $-0.23^{*}$ & 0.159 & -0.143 & $0.331^{*}$ & 0.121 & 1.000 \\
\hline
\end{tabular}

Note: $* * * \mathrm{P}<0.001, * * \mathrm{p}<0.05$

Table 3. CFA results of the measurement model

\begin{tabular}{lllcc}
\hline \multicolumn{1}{c}{ Latent Variable } & \multicolumn{1}{c}{ Measurement variables } & $\begin{array}{c}\text { Standardized factor } \\
\text { loadings }\end{array}$ & $\begin{array}{c}\text { Cronbach's } \\
\text { Alpha }\end{array}$ & AVE \\
\hline Network centrality & Closeness centrality & $0.616^{* * *}$ & 0.6958 & 0.5392 \\
& Network power & $0.836^{* * *}$ & 0.9017 & 0.8211 \\
Structural holes & Structural hole with constrain & $0.923^{* * *}$ & & 0.8597 \\
& Structural hole with hierarchy & $0.889^{* * *}$ & 0.9243 & \\
Knowledge & Knowledge diffusion by patent & $0.982^{* * *}$ & & \\
diffusion & & & & \\
& Knowledge diffusion by new & $0.869^{* * *}$ & & \\
& product & & & \\
\end{tabular}

Note: $* * *$ P<0.001; CFA Model Fit: CMIN/DF=0.743; CFI = 0.972; NFI = 0.971; RFI=0.928;

\section{Empirical results and analysis}

\subsection{Initial Structural Equation Model Setting}

The AMOS 17 software was used to set the initial structural equation model (SEM), as shown in figure 2. Business integration and brand autonomy are the explanatory variables and knowledge diffusion is the dependent variable. The acquirer's network centrality and structural hole are mediating variables influencing the relationship between integration and knowledge diffusion. GDP growth rate and R\&D investment are controls. In figure 2, the latent variables are in ellipses, the measurement variables are in rectangles, and the error items are in circles. 


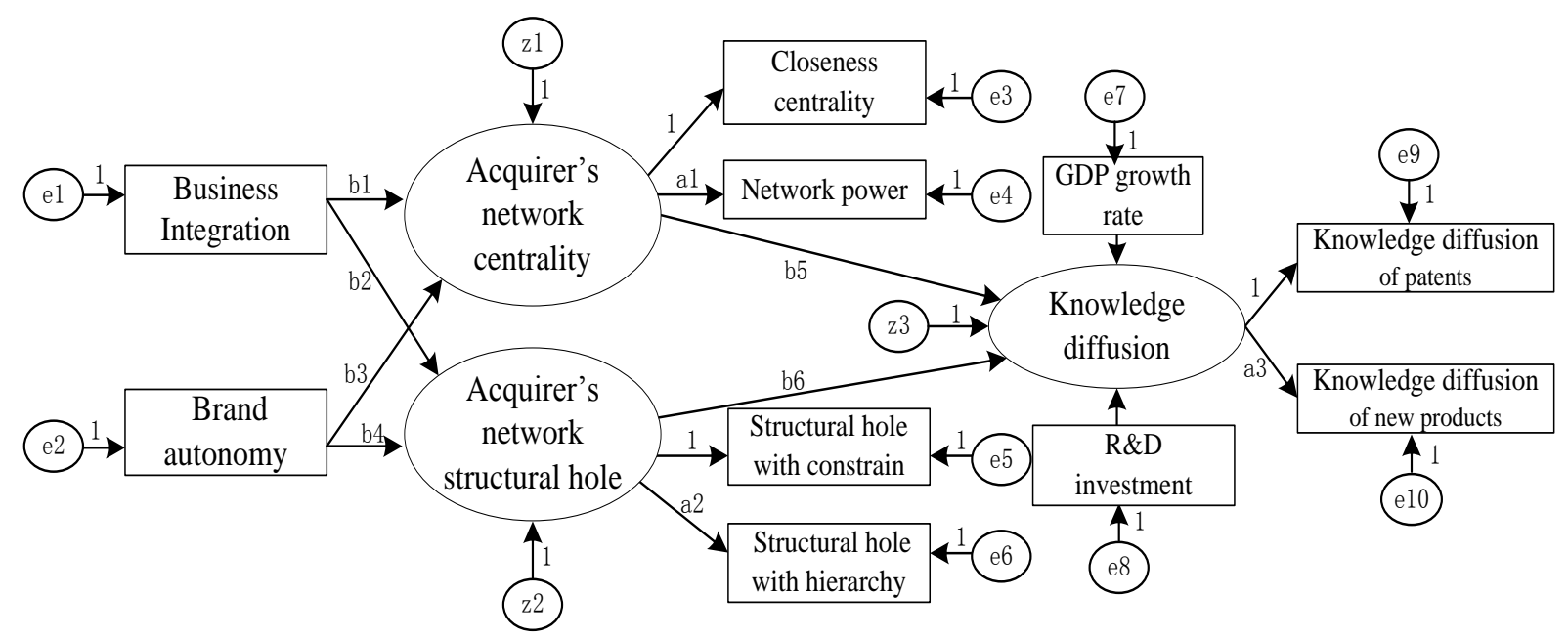

Figure 2 - The Initial path of the structural equation model

\subsection{Structural Equation Model Modification}

After running the initial model, we tested the fit index of the structure equation model, the chi square value of the initial model was 333.863, CMIN/DF $=3.21(>2)$, and RMSEA $=0.154(>0.1)$. Thus, the initial model did not meet the fit criteria, indicating that it needed further correction to improve its agreement with the actual data. In accordance with to the system, the structural equation model can be adjusted by Modification Indices, establishing relationships between Z1 and Z2, E3 and E5, and thus improving the model's degree of fit. The chi square value of the modified model was 164.137 (P < 0.001), the chi square value ratio was $1.844(<2), \mathrm{RMSEA}=0.0995(<0.1), \mathrm{CFI}=0.909(>0.9), \mathrm{IFI}$ $=0.914(>0.9)$; thus the modified model's fit meets the standard and can be used to test the hypotheses. Table 4 shows the fit indices of the initial and modified models, as well as the reference values. It can be seen that the fit indices of the structural equation model have improved after the modification. Then, we used the modified model to test our theoretical hypotheses.

Table 4. Fit indices of the initial and modified models

\begin{tabular}{c|c|c|c|c|c|c}
\hline \multirow{2}{*}{ Model } & \multicolumn{2}{|c|}{ Absolute fit index } & \multicolumn{2}{c|}{ Relative fit index } & \multicolumn{2}{c}{ Contracted fit index } \\
\cline { 2 - 7 } & CMIN/DF & RMSEA & IFI & CFI & AIC & BCC \\
\hline Initial Model & 3.210 & 0.154 & 0.826 & 0.818 & 387.499 & 477.520 \\
\hline Modified Model & 1.844 & 0.095 & 0.914 & 0.909 & 316.137 & 453.424 \\
\hline Standards & $0-2$ & $<0.1$ & $>0.9$ & $>0.9$ & $\begin{array}{c}\text { Minimum } \\
\text { principle }\end{array}$ & $\begin{array}{c}\text { Minimum } \\
\text { principle }\end{array}$ \\
\hline
\end{tabular}

\subsection{The empirical results of the structural equation model}

The empirical results of groups A (strong similarity and weak complementarity), B (weak similarity and strong complementarity), and C (strong similarity and strong complementarity) are shown in table 5. 
Table 5 Empirical results of structural equation model

\begin{tabular}{|c|c|c|c|c|c|c|c|c|}
\hline \multirow{2}{*}{ Path } & & & \multicolumn{2}{|c|}{ Group A } & \multicolumn{2}{|c|}{ Group B } & \multicolumn{2}{|c|}{ Group C } \\
\hline & & & Coefficient & S.E. & Coefficient & S.E. & Coefficient & S.E \\
\hline Network centrality & $<---$ & Business Integration & $.079 * *$ & .037 & .025 & .032 & $.400 * * *$ & .096 \\
\hline Network centrality & $<---$ & Brand autonomy & $-.055^{*}$ & .032 & -.102 & .079 & -.016 & .109 \\
\hline Structural hole & $<---$ & Business Integration & .082 & .122 & $-.391 * * *$ & .082 & -.059 & .076 \\
\hline Structural hole & $<---$ & Brand autonomy & $.574 * * *$ & .128 & $.384 * * *$ & .084 & $.285^{* * *}$ & .055 \\
\hline $\begin{array}{l}\text { Knowledge } \\
\text { diffusion }\end{array}$ & $<---$ & Network centrality & $1.545 * *$ & .500 & $.888 *$ & .486 & $1.693^{*}$ & .973 \\
\hline $\begin{array}{l}\text { Knowledge } \\
\text { diffusion }\end{array}$ & $<---$ & Structural hole & $.243 * *$ & .077 & $.271 *$ & .159 & $.168 * * *$ & .026 \\
\hline $\begin{array}{l}\text { Knowledge } \\
\text { diffusion }\end{array}$ & $<---$ & $\mathrm{R} \& \mathrm{D}$ investment & -.137 & .214 & -.104 & .317 & -.791 & .825 \\
\hline $\begin{array}{l}\text { Knowledge } \\
\text { diffusion }\end{array}$ & $<---$ & GDP growth rate & $5.707 * *$ & 2.464 & $-.009 *$ & 3.738 & 1.226 & 11.471 \\
\hline $\begin{array}{l}\text { Closeness } \\
\text { centrality }\end{array}$ & $<---$ & Network centrality & 1.000 & & 1.000 & & 1.000 & \\
\hline $\begin{array}{l}\text { Knowledge } \\
\text { diffusion by new } \\
\text { product }\end{array}$ & $<---$ & Knowledge diffusion & $.119 * * *$ & .031 & $.165^{* * * *}$ & .042 & $.783 * * *$ & .027 \\
\hline $\begin{array}{l}\text { Knowledge } \\
\text { diffusion by patent }\end{array}$ & $<---$ & Knowledge diffusion & 1.000 & & 1.000 & & 1.000 & \\
\hline $\begin{array}{l}\text { Structural hole } \\
\text { with constrain }\end{array}$ & $<---$ & Structural hole & 1.000 & & 1.000 & & 1.000 & \\
\hline $\begin{array}{l}\text { Structural hole } \\
\text { with hierarchy }\end{array}$ & $<---$ & Structural hole & $.627 * * *$ & .044 & $.687 * * *$ & .060 & $.092 * *$ & .033 \\
\hline Network power & $<---$ & Network centrality & $1.974 * * *$ & .590 & 2.338 & 1.572 & $.305 * *$ & .118 \\
\hline
\end{tabular}

Note: $* * * \mathrm{P}<0.001, * * \mathrm{P}<0.05, * \mathrm{P}<0.1$

In all three groups, network centrality and structural hole had a significant positive effect on knowledge diffusion, which supports H1. In group A, the degree of business integration was positively correlated with network centrality $(\beta=0.079, \mathrm{p}<0.05)$, autonomy and network centrality were negatively correlated $(\beta=-0.055, \mathrm{p}<0.1)$, and network centrality $(\beta=1.545, \mathrm{p}<0.05)$ and structural hole $(\beta=0.243, p<0.05)$ had a significant positive effect on knowledge diffusion capacity. In group $B$, the degree of business integration and structural hole had a significant negative correlation $(\beta=-0.391$, $\mathrm{p}<0.001)$, autonomy and structural holes had a positive correlation $(\beta=0.384, \mathrm{P}<0.001)$, and network centrality $(\beta=0.888, \mathrm{p}<0.1)$ and structural hole $(\beta=0.271, \mathrm{p}<0.1)$ were positively correlated to knowledge diffusion capacity. In group $\mathrm{C}$, the degree of integration and network centrality were positively correlated $(\beta=0.400, p<0.001)$, autonomy and structural hole had a positive correlation ( $\beta$ 
$=0.285, \mathrm{p}<0.001)$, and network centrality $(\beta=1.693, \mathrm{p}<0.1)$ and structural hole $(\beta=0.168, \mathrm{p}<0.001)$ had significant positive effects on knowledge diffusion capacity. Therefore, hypothesis $2 \mathrm{a}$ and hypothesis $3 b$ are preliminarily supported. Hypothesis $2 b$ was not confirmed. Degree of integration had no significant effect on structural hole, and autonomy was positively correlated with structural hole ( $\beta$ $=0.574, \mathrm{p}<0.001$ ), which shows that, in relation to technology-sourcing overseas M\&As, Chinese enterprises still lack the comprehensive multi-channel management ability and heterogeneity information management needed to improve on their network structural holes (Burt, 1992). The acquirer firms rely more on the targets to identify and maintain their heterogeneous networks, which is not conducive to control over the innovation network and to the optimal allocation of network resources in the case of strong resource similarity. Hypothesis $3 \mathrm{a}$ was not confirmed; in that degrees of integration and autonomy have no significant influence on network centrality. This shows that Chinese enterprises are more concentrated on absorbing and digesting their targets' resources, rather than establishing new networks. At the same time, when complementarity is strong, low levels of integration reduce the damage to the original network connection and also hinder the close interaction between the acquirer and the target's network; therefore, the relationship between degree of integration and network centrality is not significant. Hypothesis 4 was partially verified, which may be due to the small number of technology-sourcing overseas M\&As featuring both strong similarity and strong complementarity.

\subsection{Bootstrap Test}

In order to further test the empirical results of the stepwise regression analysis, this paper used Chadwick et al.'s (2015) bootstrap measure to test the intermediary effects of the global network position on the relationship between integration mode and knowledge diffusion. We only tested the significant relationships shown in table 4 . We set the number of bootstrap samples at 500 and the bilateral biascorrection interval at 95\%, and the results are shown in Table 6. In the presence of strong resource similarity and strong resource complementarity between the acquiring and acquired firms, the integration degree and knowledge diffusion coefficient through network centrality was positive $(\beta=$ $0.0339)$, and lower than that related to strong similarity and weak complementarity $(\beta=0.061)$. In this case, brand autonomy had a positive correlation with knowledge diffusion capacity through network structure $(\beta=0.011)$, lower than that related to weak similarity and strong complementarity $(\beta=0.144)$.

Table 6 Bootstrap tests

\begin{tabular}{|c|c|c|c|}
\hline Group & Intermediary effect & Coefficient & P value \\
\hline \multirow{3}{*}{$\begin{array}{l}\text { Strong similarity } \\
\text { and weak } \\
\text { complementarity }\end{array}$} & $\begin{array}{l}\text { Business Integration } \rightarrow \text { Network centrality } \rightarrow \text { knowledge diffusion } \\
\text { capacity }\end{array}$ & 0.061 & $0.061^{*}$ \\
\hline & $\begin{array}{l}\text { Brand autonomy } \rightarrow \text { Network centrality } \rightarrow \text { knowledge diffusion } \\
\text { capacity }\end{array}$ & -0.044 & $0.02^{* *}$ \\
\hline & Brand autonomy $\rightarrow$ Structural hole $\rightarrow$ knowledge diffusion capacity & 0.003 & 0.844 \\
\hline
\end{tabular}




\begin{tabular}{l|l|c|c}
\hline $\begin{array}{l}\text { Weak similarity } \\
\text { and strong }\end{array}$ & $\begin{array}{l}\text { Business Integration } \rightarrow \text { Network centrality } \rightarrow \text { knowledge diffusion } \\
\text { capacity }\end{array}$ & -0.170 & $0.079^{*}$ \\
\cline { 2 - 4 } & Brand autonomy $\rightarrow$ Structural hole $\rightarrow$ Knowledge diffusion & 0.144 & $0.047^{* *}$ \\
\hline $\begin{array}{l}\text { Strong similarity } \\
\text { and strong } \\
\text { complementarity }\end{array}$ & Business Integration $\rightarrow$ Network centrality $\rightarrow$ knowledge diffusion & 0.039 & $0.043^{* *}$ \\
\cline { 2 - 4 } & Brand autonomy $\rightarrow$ Structural hole $\rightarrow$ knowledge diffusion & 0.011 & $0.045^{*}$ \\
\hline
\end{tabular}

Note: $\quad * * \mathrm{P}<0.05, * \mathrm{P}<0.1$

\section{Discussion and conclusion}

We studied how the PMI of technology-sourcing overseas M\&As improves industrial-level innovation performance based on the centrality and structural hole of the global innovation network. We combined resource orchestration theory and innovation network theory to demonstrate our hypotheses empirically by adopting multiple-group structural equation modelling and bootstrap testing based on a sample of listed Chinese manufacturing companies. This paper draws the following conclusions: (1) the more central the position of the acquirer in the global innovation network, the stronger its knowledge diffusion capacity in the wake of an overseas M\&A; (2) the stronger the acquirer's structural hole in the innovation network, the stronger its knowledge diffusion capacity in the wake of an overseas M\&A; (3) in the presence of strong resource similarity and weak resource complementarity between the acquiring and acquired firms, high levels of business integration and low levels of brand management autonomy will be more suited to improve the acquirer's network centrality; (4) in the presence of weak resource similarity and strong resource complementarity between the acquiring and acquired firms, low levels of business integration and high levels of brand management autonomy will be more suited to strengthen the acquirer's network structural hole; (5) in the presence of strong resource similarity and strong resource complementarity between the acquiring and acquired firms, moderate levels of integration are more suited to improve the acquirer's network centrality, and moderate levels of autonomy are more suited to strengthen the acquirer's network structural hole.

\subsection{Theoretical implications}

Our theoretical contributions are threefold. First, by examining the interaction of resources, such as business and brand integration in EMNE M\&As, our study provides deeper insights and distinguishes the actual PMI factors that explain the variance in post-merger performance. Identifying the appropriate integration mode under which knowledge can be effectively diffused during M\&A implementation has the potential to contribute not only to the knowledge management literature, but also to the broader M\&A literature. Previous research highlighting the benefits of acquisitions for knowledge transfer purposes suggested relatively high levels of integration (Ranft and Lord, 2002; Ranucci and Souder, 2015; Sarala et al., 2016). However, our research found that, in order to promote knowledge diffusion 
in the wake of overseas M\&As, EMNEs may take different PMI approaches. We unpacked the notion of PMI by distinguishing business integration and brand integration. In doing so, we contributed to gaining a nuanced understanding of PMI and of its impact on knowledge diffusion. Recent research found that EMNEs tend to adopt dynamic approaches to brand management after overseas acquisitions (Liu et al., 2018). Our findings lend further support to this observation by articulating the different combinations of business integration and brand integration that may variously impact on knowledge diffusion.

Second, this paper builds upon a micro-foundational perspective by examining the connection between resource similarity and complementarity in the pre-merger stage and integration mode in the post-merger one in explaining the performance of knowledge diffusion in the context of EMNEs. Our findings indicate that EMNEs may also adopt high degrees of integration, but only in the presence of a certain level of resource similarity between the acquiring and target firms. Moreover, the scope of integration pertains only to activities rather than to brand or culture (Ahammad et al., 2016). Our results highlight how resource similarity is more important for the integration and knowledge management of EMNEs; this is due to the liabilities of emergingness, with their significant culture distances and location-based management practices that cannot be transferred to mature markets (Buckley et al., 2017; RaoNicholson et al., 2016). In so doing, our research contributes to gaining a nuanced understanding of PMI by revealing the modes of resource integration adopted by EMNEs and their different effects on knowledge diffusion, rather than relying on a 'one-size-fits-all' notion of high autonomy. Our research juxtaposes the M\&A literature with the recent micro-foundational movement in management and organization studies by articulating resource recognition and interaction as one important microfoundation for the macro-level outcomes of M\&As.

Third, we contribute to the understanding of knowledge diffusion in M\&As from a network perspective by highlighting the important role played by the global network position held by the acquiring firm and its impact on the inter-organization diffusion of knowledge, in the post-M\&A stage, from acquiring to target firms within the same industry. Recent work suggests that M\&As should not be viewed as isolated bilateral relationships, but that behaviours of network embeddedness should be recognized, by which actors outside the organization boundaries - e.g., customers, supplies and partners—should be taken into account (Wang and Zajac, 2007; Lin et al., 2009; Sarala et al.,2017). Exequiel and Anoop (2018) indicated that M\&As enable acquirers to improve their knowledge-enhancing positions in networks, such as their centrality or structural holes, by bringing about not only 'internal synergies' with the targets' resources, but also 'network synergies' by inheriting the targets' network ties. In this paper, we argue that the PMI stage is more important than the M\&A transaction to realize network synergy. We contribute to the literature on the network synergy of cross-border M\&As by constructing a framework matching the resource attributes in the pre-merger stage with the integration mode in the post-merger 
one (Haleblian et al., 2009; Weber et al.,2011; Gomes et.al, 2013) and by further exploring the impact of different integration modes on network externality, preference attachment, and network collapse.

\subsection{Managerial implications}

Technology-sourcing overseas M\&As are an effective way in which firms from emerging markets can rapidly access innovative knowledge and valuable resources. In choosing their overseas targets, EMNEs should not only evaluate the latter's own finances, management teams and technologies, but should also pay attention to their external network relationship resources, such as innovation cooperation, supply chains, and customers. M\&As enable actors to gain control over two types of resources: the targets' internal ones, to bring about 'internal synergies'; and the external ones gained from inheriting the targets' network ties to bring about 'network synergies' (Exequiel and Anoop, 2018); Overseas M\&As have been found to be effective means for acquirers to improve their knowledge-enhancing positions, such as centrality or structural holes (Anjos and Fracassi, 2015; Buskens and Rijt, 2008), when the appropriate integration mode is implemented. For acquiring firms from emerging markets, granting high levels of autonomy to target firm TMTs or effecting light-touch integration are not the only choices in post-merger management. Business integration can be carried out when a certain similarity of resources exists between the acquiring and target firms. Thus, EMNEs should not blindly imitate the internationalization modes - or even the PMI modes - of well-known flagship enterprises from their home countries (Oehme and Bort, 2015), such as the high autonomy of the 'Geely Mode', which tends to ignore the real situation of the underlying resource integration that the acquired firm has not disclosed. We suggest that private equity investors, professional consulting firms and technical experts should participate in the overseas M\&As of EMNEs, helping to judge the resource base of the acquiring and target firms, and provide matched integration modes and knowledge management solutions.

\subsection{Limitations and directions for future research}

Although this study offers an empirical validation of some important tenets of knowledge research, it also has several limitations worth discussing. In the study of overseas M\&As, China is often regarded as a typical emerging market (Zhang et al., 2015; Chen et al., 2017; Khan et al., 2018). We suggest that the findings of this paper could be extended to acquirers from all other emerging markets, as EMNEs faces similar liabilities of emergingness when trying to invest in developed countries (Buckley et al., 2017; Rao-Nicholson et al., 2016). Future studies could develop further empirical comparative analyses of MNEs from other emerging markets, such as India or Russia. Moreover, the collection of qualitative data falls outside of the scope of this paper, but should be considered in the future in order to offer a more nuanced and contextualized understanding from the micro-foundational perspective. Finally, a structural equation model as ours combines multiple regression, path analysis, factor analysis, and covariance analysis, which make up for the shortcomings of traditional statistical methods that cannot 
test for mediation effects (Chadwick et al., 2015). The bootstrap method has been used to prove the robustness of mediation effects by resampling the observed samples and excavating any hidden information (Alfons et.al., 2018). The intermediary effects of the global network position on the relationship between integration mode and knowledge diffusion are tested to be robust. However, network position would affect the choice of internationalization mode and integration mode (Oehme and Bort, 2015). This type of endogeneity needs to be tested by future research. 


\section{REFERENCES}

Ahammad, M. F. , Tarba, S. Y. , Liu, Y. , and Glaister, K. W. (2016), "Knowledge transfer and cross-border acquisition performance: The impact of cultural distance and employee retention", International Business Review, Vol. 25 No. 1,pp. 66-75.

Aklamanu, A. , Degbey, W. Y. , and Tarba, S. Y. (2016), "The role of HRM and social capital configuration for knowledge sharing in post-M\&A integration: A framework for future empirical investigation", The International Journal of Human Resource Management, Vol. 27 No. 22, pp. 2790-2822.

Ahuja, G., and Katila, R. (2001), "Technological acquisitions and the innovation performance of acquiring firms: a longitudinal study", Strategic Management Journal, Vol. 22 No. (3), pp. 197-220.

Alfons, A., Ates, N., and Groenen, P. J. F. (2018), A robust bootstrap test for mediation analysis, Social Science Electronic Publishing.

Alguezaui, S., and Filieri, R. (2010), "Investigating the role of social capital in innovation: sparse versus dense network", Journal of Knowledge Management, Vol.14 No.6, pp. 891-909.

Anjos, F., \& Fracassi, C. (2015), "Shopping for Information? Diversification and the Network of Industries", Management Science, Vol. 61 No1, pp. 161-183.

Awazu, Y. (2004), “Informal network players, knowledge integration, and competitive advantage”, Journal of Knowledge Management, Vol. 8 No.3,pp. 62-70.

Banalieva, E. R., and Dhanaraj, C. (2013), "Home-region orientation in international expansion strategies", Journal of International Business Studies, Vol. 44 No.2, pp. 89-116.

Bauer, F., and Matzler, K. (2014), "Antecedents of m\&a success: the role of strategic complementarity, cultural fit, and degree and speed of integration”, Strategic Management Journal, Vol. 35 No.2, pp. 269291.

Borgatti, S. P.and Halgin, D. S. (2011), “On network theory”, Organization Science, Vol. 22 No.5, pp. 1168 1181.

Burt.RS (1992), Structure Holes: The Social Structure of Competition, Explorations in economic

Buskens, V., and Rijt, A. V. D. (2008), "Dynamics of networks if everyone strives for structural holes", American Journal of Sociology, Vol.114 No.2, pp. 371-407.

Caiazza, R., Véry, P., and Ferrara, G. (2017), "New geography of M\&As: A framing device of firms' strategies", Thunderbird International Business Review, Vol. 59 No.2, pp. 243-250.

Chadwick, C., Super, J. F., and Kwon, K. (2015), "Resource orchestration in practice: ceo emphasis on shrm, commitment-based hr systems, and firm performance", Strategic Management Journal, Vol. 36 No.3, pp. $360-376$. 
Cho, Y., Hwang, J., and Lee, D. (2012), "Identification of effective opinion leaders in the diffusion of technological innovation: a social network approach”, Technological Forecasting \& Social Change, Vol. 79 No.1, pp. 97-106.

Colombo MG and Rabbiosi L. (2014), "Technological similarity, post-acquisition R\&D reorganization, and innovation performance in horizontal acquisitions”, Research Policy, Vol. 43 No.6, pp.1039-1054

Cording, M., Christmann, P. and King, D. R. (2008), "Reducing Causal Ambiguity in Acquisition Integration: Intermediate Goals as Mediators of Integration Decisions and Acquisition Performance", Academy of Management Journal, Vol.51 No.4, pp.744-767.

Dao et al. (2017). Triggering innovation through mergers and acquisitions: the role of shared mental models. Group \& Organization Management, 42(2), 195-236.

Degbey W. and Pelto E. (2013), "Cross-border M\&A as a trigger for network change in the russian bakery industry”, Journal of Business \& Industrial Marketing, Vol. 28 No.3 pp. 178-189.

Driffield, N., Love, J. H., and Taylor, K. (2009), "Productivity and labour demand effects of inward and outward foreign direct investment on UK industry", The Manchester School, Vol. 77 No. 2, pp. 171-203.

Ernst, D., and Kim, L. (2001), "Global productions networks, knowledge diffusion, and local capability formation. a conceptual framework", Research Policy, Vol. 31 No. 8, pp. 1417-1429.

Exequiel Hernandez, Anoop Menon. (2018), “Acquisitions, Node Collapse, and Network Revolution”, Management Science, Vol. 64 No. 4. pp. 1652-1671.

Felin, T., Foss, N. J., and Ployhart, R. E. (2015), “The microfoundations movement in strategy and organization theory". Academy of Management Annals, Vol. 9 No.1.pp. 575-632.

Freeman, C. (1991), "Networks of innovators: a synthesis of research issues". Research policy, Vol. 20 No.5, pp.499-514.

Gomes, E. , Angwin, D. N., Weber, Y. , and Yedidia Tarba, S. (2013), "Critical success factors through the mergers and acquisitions process: Revealing pre - and post - M\&A connections for improved performance”, Thunderbird International Business Review, Vol.55 No.1, pp. 13-35.

Graebner, M. E., Heimeriks, K. H., Huy, Q. N., and Vaara, E. (2017), “The process of postmerger integration: A review and agenda for future research", Academy of Management Annals, Vol. 11 No.1, pp. 1-32.

Guan, J., and Chen, Z. (2012), "Patent collaboration and international knowledge flow", Information Processing \& Management, Vol. 48 No. 1, pp. 170-181.

Guan, J. C., Zuo, K. R., Chen, K. H., and Yam, R. C. M. (2016), "Does country-level r\&d efficiency benefit from the collaboration network structure?”, Research Policy, Vol. 45 No. 4, pp. 770-784. 
Haleblian, J., Devers, C.E., McNamara, G., Carpenter, M.E., and Davison, R.B. (2009), “Taking stock of what we know about mergers and acquisitions: A review and research agenda", Journal of Management, Vol. 35 No.3, pp. 469-502.

Hanaki, N., Nakajima, R., and Ogura, Y. (2010), “The dynamics of r\&d network in the it industry”, Research Policy, Vol. 39 No. 3, pp. 386-399.

Helfat, C. E., and Peteraf, M. A. (2003), "The dynamic resource - based view: capability lifecycles”. Strategic Management Journal, Vol. 24 No.10, pp. 997-1010.

Herrigel, G., Wittke, V., and Voskamp, U. (2013), "The process of Chinese manufacturing upgrading: transitioning from unilateral to recursive mutual learning relations", Global Strategy Journal, Vol. 3 No. 1, pp. 109-125.

Johnson, J. C., Boster, J. S., and Holbert, D.(1989), "Estimating relational attributes from snowball samples through simulation", Social Networks, Vol. 11 No. 2, pp. 135-158.

Junni, P., Sarala, R. M. , Tarba, S. Y., and Weber, Y. (2015), “The role of strategic agility in acquisitions”, British Journal of Management, Vol. 26 No. 4, pp. 596-616.

Khan, Z., Wood, G., Tarba, S. Y., Rao-Nicholson, R., and He, S. (2018), "Human resource management in Chinese multinationals in the United Kingdom: The interplay of institutions, culture, and strategic choice", Human Resource Management. available at: https://doi.org/10.1002/hrm.21935

Kim, H., and Park, Y. (2009), "Structural effects of R\&D collaboration network on knowledge diffusion performance", Expert Systems with Applications, Vol. 36 No. 5, pp.8986-8992.

Koka, B. R., and Prescott, J. E. (2008), "Designing alliance networks: the influence of network position, environmental change, and strategy on firm performance", Strategic Management Journal, Vol.29 No.6, pp. 639-661.

Kuemmerle, W. (1999), “The Drivers of Foreign Direct Investment into Research and Development: An Empirical Investigation”, Journal of International Business Studies, Vol. 30 No.1, pp. 1-24.

Lakshman, C. (2011), "Post-acquisition cultural integration in mergers and acquisitions: A knowledge-based approach", Human Resource Management, Vol. 50 No. 5, pp. 605-623.

Lin, Z. J., Peng, M. W., Yang, H., and Sun, S. L. (2009), "How do networks and learning drive M\&As? An institutional comparison between China and the United States", Strategic Management Journal, Vol. 30 No.10, pp. 1113-1132.

Lin, Z., Yang, H., and Demirkan, I. (2010), "The performance consequences of ambidexterity in strategic alliance formations: empirical investigation and computational theorizing”. Management Science, Vol. 34 No. 6, pp. 3075-3076. 
Liu, Y., Oberg, C., Tarba, S. Y., and Xing, Y.(2018), "Brand management in Mergers and Acquisitions: Emerging market multinationals venturing into advanced economies", International Marketing Review, Vol. 35 No. 5, pp. 710-732.

Liu, Y., and Meyer, K.E. (2018), "Boundary spanners, HRM practices, and reverse knowledge transfer: The case of Chinese cross-border acquisitions", Journal of World Business, available at: https://doi.org/10.1016/j.jwb.2018.07.007.

Liu, Y. and Vrontis, D. (2017), "Emerging markets firms venturing into advanced economies: The role of context”, Thunderbird International Business Review, Vol. 59 No.3, pp. 255-161.

Liu, Y.and Woywode, M. (2013), "Light-touch Integration of Chinese Cross-Border M\&A: The Influences of Culture and Absorptive Capacity", Thunderbird International Business Review, Vol. 55 No.4, pp. 469483.

Luo, S. , Du, Y., Liu, P. , Xuan, Z. , and Wang, Y. (2015), "A study on coevolutionary dynamics of knowledge diffusion and social network structure", Expert Systems with Applications, Vol. 42 No.7, pp.36193633.

Iurkov, V., and Benito, G. R. G. (2017), "Domestic alliance networks and regional strategies of mnes: a structural embeddedness perspective”, Journal of International Business Studies, Vol. 49 No.8, pp. 10331059

Madhok A, Keyhani M. (2012), “Acquisitions as entrepreneurship: Asymmetries, opportunities, and the internationalization of multinationals from emerging economies", Global Strategy Journal, Vol 2 No. 1, pp. $26-40$.

Makri, M., Hitt, M. A., and Lane, P. J. (2010), “Complementary technologies, knowledge relatedness, and invention outcomes in high technology mergers and acquisitions", Strategic Management Journal, Vol. 31 No. 6, pp. 602-628.

McEvily, B. and Zaheer, A.(1999), "Bridging Ties: A Source of Firm Heterogeneity in Competitive Capabilities", Strategic Management Journal, Vol.20 No. 12, pp.1133-1156.

Ministry of Commerce of the People's Republic of China. (2018), 2017 Annual Report on China's Foreign Direct Investment, China Statistics Press, Beijing, BJ

Monge, P. R., and Contractor, N. S. (2003), Theories of Communication Networks, Oxford University Press. Mu, Q. , and Lee, K. (2005), "Knowledge diffusion, market segmentation and technological catch-up: the case of the telecommunication industry in china”, Research Policy, Vol. 34 No. 6, pp. 759-783.

Oehme, M. , and Bort, S. (2015). "Sme internationalization modes in the german biotechnology industry: the influence of imitation, network position, and international experience", Journal of International Business Studies, Vol. 46 No. 6, pp. 629-655. 
Park, K. M., Meglio, O., Bauer, F., and Tarba, S. (2018), "Managing patterns of internationalization, integration, and identity transformation: The post-acquisition metamorphosis of an Arabian Gulf EMNC", Journal of Business Research. available at: https://doi:10.1016/j.jbusres.2018.05.019

Palepu, Tarun Khanna, Krishna G. (2010), How To Define Emerging Markets, Forbes.

Paruchuri, S., Nerkar, A. and Hambrick, D. C. (2006), “Acquisition Integration and Productivity Losses in the Technical Core: Disruption of Inventors in Acquired Companies", Organization Science, Vol.17 No.5, pp. 545-562.

Puranam, P., Singh, H. and Chaudhuri, S.(2009), "Integrating Acquired Capabilities: When Structural Integration is (Un) Necessary", Organization Science, Vol. 20 No.2, pp. 313-328

Puranam, P., Singh, H., and Zollo, M. (2006), “Organizing for innovation: Managing the coordinationautonomy dilemma in technology acquisitions", Academy of Management Journal, Vol. 49 No.2, pp. 263280.

Qian Xihong, Yang Yongfu and Xu Wanli . (2010), “The Position of Firms' Network, the Absorptive Capacity, and the Performance in Innovation”. Management World, Vol. 31 No.5, pp. 118-129.

Ranucci, R. A., and Souder, D. (2015), "Facilitating tacit knowledge transfer: routine compatibility, trustworthiness, and integration in m\&as", Journal of Knowledge Management, Vol.19 No.2, pp. 257-276.

Raonicholson, R., Khan, Z., Akhtar, P., and Tarba, S. Y. (2016), "The contingent role of distributed leadership in the relationship between HR practices and organizational ambidexterity in the cross-border M\&As of emerging market multinationals", The International Journal of Human Resource Management, pp. $1-22$.

Rowley, T. J., and Baum, J. A. (2008). "The dynamics of network strategies and positions", Advances in Strategic Management, Vol. 97 No.25, pp. 641-671.

Sarala, R. M., Vaara, E., and Junni, P. (2017), "Beyond merger syndrome and cultural differences: New avenues for research on the "human side" of global mergers and acquisitions (M\&As)", Journal of World Business. available at: https://doi.org/10.1016/j.jwb.2017.10.001

Sarala, R.M., Junni, P., Cooper C.L., and Tarba, S. Y. (2016), “A sociocultural perspective on knowledge transfer in mergers and acquisitions", Journal of Management, Vol.42 No.5, pp. 1230-1249.

Shi, T., Li, J., and Chi, L. (2017), "Host country consumers' brand attitudes after cross-border-acquisitions", Journal of Product \& Brand Management, Vol. 26 No.3, pp. 559-572.

Sirmon DG. , Hitt MA., Ireland R.D, and Gilbert BA. (2011), "Resource Orchestration to Create Competitive Advantage: Breadth, Depth, and Life Cycle Effects”, Journal of Management, Vol. 37 No. 5, pp.1390-1412.

Sirmon, D. G., and Ireland, R. D. (2009), "Managing firm resources in dynamic environments to create value: looking inside the black box", Academy of Management Review, Vol. 32 No.1, pp. 273-292. 
Slangen, A. H. (2006), "National cultural distance and initial foreign acquisition performance: The moderating effect of integration". Journal of World Business, Vol. 41 No.2, pp. 161-170.

Sun, Y., and Du, D. (2010), "Determinants of industrial innovation in China: Evidence from its recent economic census". Technovation, Vol. 30 No.9, pp. 540-550.

Tarba, S. Y., Ahammad, M. F., Junni, P., Stokes, P., and Morag, O. (2017), “The Impact of Organizational Culture Differences, Synergy Potential, and Autonomy Granted to the Acquired High-Tech Firms on the M\&A Performance", Group \& Organization Management, available at: https://doi.org/10.1177/1059601117703267

Vonortas, N. S. (2009), Innovation networks in industry. Chapters.

Vũ, D. A., Shi, Y., and Hanby, T. (2009), "Strategic framework for brand integration in horizontal mergers and acquisitions", Journal of Technology Management in China, Vol. 4 No.1, pp. 26-52.

Wang, C., Rodan, S., Fruin, M., and Xu, X. (2014), "Knowledge networks, collaboration networks, and exploratory innovation”, Academy of Management Journal, Vol. 57 No.2, pp. 484-514.

Wang, L., and Zajac, E. J. (2007), "Alliance or acquisition? a dyadic perspective on interfirm resource combinations", Strategic Management Journal, Vol. 28 No.13, pp. 1291-1317.

Wang, X., Xi, Y., Xie, J., Zhao, Y., and Wang, X., et al. (2017), “Organizational unlearning and knowledge transfer in cross-border m\&a: the roles of routine and knowledge compatibility". Journal of Knowledge Management, Vol. 21 No. 6, pp.1580-1595.

Wang Weiguang, Feng Rongkai, and Yin bo. (2015), "Whether the control of the core enterprise in the industrial innovation network can promote the knowledge spillover?", Management world, No. 6, pp.99-109.

Weber, Y., and Tarba, S. Y. (2011), "Exploring culture clash in related mergers: Post-merger integration in the high-tech industry", International Journal of Organizational Analysis, Vol. 19 No.3, pp. 202-221.

Weber, Y., Tarba, S. Y., and Reichel, A. (2009), International mergers and acquisitions performance revisited-The role of cultural distance and post-acquisition integration approach. In C. Cooper \& S. Finkelstein(Eds.), Advances in Mergers and Acquisitions (8th ed.). New York,

Wu Jingfei and Rui Mingjie. (2007), “A Research on the Dynamics of Industry Modularization”, Management world, No. 10,pp. 75-83.

Xing, Y., Liu, Y., Tarba, S. Y., and Cooper, C. (2017), "Servitization in mergers and acquisitions: Manufacturing firms venturing from emerging markets into advanced economies", International Journal of Production Economics, No.192, pp. 9-18.

Yakob, R., Nakamura, H. R., and Ström, P. (2018), "Chinese foreign acquisitions aimed for strategic assetcreation and innovation upgrading: the case of geely and volvo cars". Technovation, Vol. 70 No.2, pp. 5972. 
Yoon, H., and J. J. Lee. (2016), "Technology-acquiring Cross-border M\&As by Emerging Market Firms: Role of Bilateral TradeOpenness", Technology Analysis \& Strategic Management, Vol. 28 No. 3, pp. 251265

Zaheer, A. and Bell, G. G. (2005), "Benefiting from Network Position: Firm Capabilities, Structural holes, and Performance", Strategic Management Journal, Vol.26 No. 9, pp.809-825.

Zaheer, A., Castañer, X. and Souder, D. (2013), "Synergy Sources, Target Autonomy, and Integration in Acquisitions", Journal of Management, Vol. 39 No.3, pp. 604-632

Zhang, J. , Ahammad, M. F. , Tarba, S. , Cooper, C. L. , Glaister, K. W. , and Wang, J. (2015), "The effect of leadership style on talent retention during merger and acquisition integration: evidence from china", The International Journal of Human Resource Management, Vol. 26 No.7, pp. 1021-1050.

Zou, H., and Ghauri, P. N. (2008), "Learning through international acquisitions: The process of knowledge acquisition in China". Management International Review, Vol. 48 No. 2, pp. 207-226. 